Józef Stala

The Pontifical University of John Paul II in Krakow, Poland

\title{
Handlungskompetenzen des Religionslehrers und Katecheten, eine an der Vermittlung pädagogischer und katechetischer Fähigkeiten orientierte Ausbildung
}

\section{The Action-Related Competence of RE Teacher and Catechist. Toward the development of pedagogical and catechetical skills}

\begin{abstract}
RE teachers are required to demonstrate the professional, theological, psychological and pedagogical knowledge and skills delineated in professional and institutional standards to facilitate the process of learning and upbringing. True respect for the pupils does not only call RE teacher for the adaptation of the teaching method, but also demands to develop many skills and undertake the emotional, intellectual, personal and religious formation. Handlungskompetenzen (the actionrelated competencies) seems to be very important for every teacher, but especially for RE teacher and catechist, because they are influenced by teacher's beliefs and values. These competencies are the complex abilities needed to enact spontaneously specific knowledge in learning situation. This paper highlights the importance of the teachers' actions or reactions in critical and/or challenging teaching/learning situations and ability to explain a topic in the response to pupils' difficulty and questions. Equipping RE teachers and catechists to meet the needs of diverse pupils means also to help them in planning the educational actions and critical evaluation of didactical processes. Consequently, RE teacher or catechist needs to be not only a teacher, but also pedagogue and faith witness. Therefore, he/she should be characterized by a willingness to lifelong learning, enthusiasm for self-study and broad mindedness.
\end{abstract}

\section{Keywords}

RE teacher, catechist, action-related competencies. 
In seinem apostolischen Schreiben „Catechesi tradendae” erinnerte der Heilige Vater Johannes Paul II. daran, dass ,es bei der heutigen Lage der Katechese Gründe der Methodik oder Pädagogik ratsam erscheinen lassen, die Vermittlung des reichen Inhaltes der Katechese auf diese und nicht auf eine andere Weise durchzuführen. Im übrigen dispensiert die Vollständigkeit ja nicht vom Bemühen um Gleichgewicht, um einen organischen und gestuften Aufbau, durch den man den darzubietenden Wahrheiten, den zu vermittelnden Normen wie den aufzuzeigenden Möglichkeiten des christlichen Lebens das ihnen jeweils entsprechende Gewicht zuteilt. Es kann auch sein, dass sich eine bestimmte Sprache für die Übermittlung dieses Inhaltes an diese Person oder Gruppe von Personen als geeigneter erweist. Die getroffene Wahl wird insoweit gelten können, wie sie nicht von mehr oder weniger subjektiven Theorien und Vorurteilen ausgeht oder von einer bestimmten Ideologie geprägt ist, sondern vom demütigen Bestreben, einem Inhalt noch besser gerecht zu werden, der voll und ganz erhalten bleiben muss. Methode und Sprachform, die man verwendet, müssen wirklich Werkzeuge bleiben, um die Gesamtheit und nicht nur einen Teil der 'Worte des ewigen Lebens' oder von den 'Wegen des Lebens' mitzuteilen"'. Die Ausbildung der Religionslehrer und Katecheten soll folgende Elemente berücksichtigen und harmonisch miteinander verbinden: sein, wissen und können ${ }^{2}$. Neben der geistigen und intellektuellen Bildung ist die Befähigung zum praktischen Handeln ebenso wichtig, das heißt Lehrer, Erzieher und Glaubenszeuge sein zu können. Der Bereich der Handlungskompetenzen ist von gleichrangiger Bedeutung, da die Katechese ja einen Kommunikationsakt darstellt ${ }^{3}$. Die Ausbildung sucht den Katecheten zu einem Erzieher des Menschen und des menschlichen Lebens zu machen ${ }^{4}$. Darum erscheint es nur

1 Catechesi tradendae 31.

2 Vgl. Dyrektorium katechetyczne Kościoła katolickiego w Polsce 155.

3 Vgl. E. Osewska, Modele komunikacji interpersonalnej i ich znaczenie dla katechezy, in: Wybrane zagadnienia z katechetyki, Hrsg. J. Stala, Tarnów 2003, S. 111-139; S. Gatt, H. Lombaerts, E. Osewska, A. Scerri, Catholic Education, European and Maltese Perspectives. Church School's response to future challenges, Floriana 2004; H. Lombaerts, Komunikacja wiary dzisiaj, in: Komunikacja wiary w Trzecim Tysiacleciu, Hrsg. S. Dziekoński, Olecko 2000, S. 25-39; E. Osewska, W poszukiwaniu modeli wychowania młodzieży ku wartościom, in: Katechizować dzisiaj. Problemy i wyzwania, Hrsg. J. Stala, Kielce 2004, S. 193-209; B. Harwas-Napierała, Komunikacja interpersonalna w rodzinie, Poznań 2008; A.W. Janke, Transformacja w stosunkach rodziny i szkoty na przełomie XX/XXI wieku. Perspektyw zmiany społecznej w edukacji, Bydgoszcz 2002.

4 Vgl. Directorium catechisticum generale 238. 
zu berechtigt, in dem vorliegenden Artikel die Frage aufzugreifen, wie den Handlungskompetenzen des Religionslehrers und Katecheten mehr Gewicht verliehen werden und der Blick verstärkt auf die Ausbildung pädagogischer und katechetischer Fähigkeiten gelenkt werden kann. Die einzelnen Teile befassen sich folglich mit dem Religionslehrer und Katecheten in seinen Funktionen als Lehrer, Erzieher und Glaubenszeuge.

\section{Der Religionslehrer und Katechet als Lehrer}

Die Weitergabe katechetischer Inhalte geschieht im Religionsunterricht oder während der Katechese. Wenn man vom Religionsunterricht oder von der Katechese spricht, muss man sich auf die Person beziehen, die diese durchführt. Es ist offensichtlich, dass der Religionslehrer und Katechet seinen Unterricht auf interessante, ansprechende, dynamische und methodologisch korrekte Art und Weise gestalten sollte. Für eine derartige Unterrichtsführung sind entsprechende didaktische Befähigungen notwendig 5 . Um diese zu erwerben, muss ein „wahrer” Lehrer seine eigenen Kompetenzen kontinuierlich erweitern sowie beständig um die Vertiefung seines Wissens und seiner Fähigkeiten zu dem spezifischen Unterrichtsgegenstand bemüht sein. $\mathrm{Zu}$ den didaktischen Kompetenzen zählen die Befähigung, den Unterricht für das gesamte Schuljahr richtig zu planen, die einzelnen Unterrichtsstunden logisch zu konstruieren, die spezifischen Strukturen der Stunden zu erfassen und jedes Element des Lernprozesses zu bewerten, die Lernziele zu operationalisieren, bei der Durchführung des Unterrichts empfindsam für die Sozialtechniken zu werden - der Aktivierung genügend Raum zu gewähren, ihrer Faszination

Vgl.C.M. Sondej,Intelektualnaiduchowaformacjaosobowościkatechetekw Międzyzakonnym Wyższym Instytucie Katechetycznym w Krakowie, Kraków 1998, S. 265; Dydaktyka katechezy. Część I, Hrsg. J. Stala, Tarnów 2004; Dydaktyka katechezy. Część II, Hrsg. J. Stala, Tarnów 2004; J. Stala, E. Osewska, Anders erziehen in Polen. Der Erziehungs- und Bildungsbegriff im Kontext eines sich ständig verändernden Europas des XXI. Jahrhunderts, Tarnów 2009; J. Stala, W kierunku integralnej edukacji religijnej w rodzinie. Próba refleksji nad nauczaniem Jana Pawła II w kontekście polskich uwarunkowań, Tarnów 2010; E. Osewska, Możliwości i ograniczenia polityki rodzinnej w krajach Unii Europejskiej, in: Rodzina jako środowisko rozwoju człowieka, Hrsg. W. Piotrowski, Tarnów 2004, S. 89-119; H. Lombaerts, E. Osewska, Family and Family Catechesis. A Matter of Diversification, „Acta Paedagogica Vilenensia” (2008), Vol. 20, S. 225-243; E. Osewska, J. Stala, Catholic School. Polish perspective, "Rivista lasalliana" 75 (2008) Nr. 2, S. 241-246. 
aber auch nicht übermäßig zu erliegen ${ }^{6}$. In der heutigen Zeit soll der Lehrer eine von der modernen Didaktik postulierte kreative Grundeinstellung im Bereich der Methoden und der didaktischen Hilfsmittel einnehmen, da er sich nicht darauf beschränken kann, den Religionsunterricht lediglich in der Form einer Darbietung durchzuführen ${ }^{7}$. In dieser Forderung drückt sich die Sorge darum aus, dass der Religionslehrer und Katechet die Religionsstunde und die Katechese klar und geordnet aufbaut, dass er sie entsprechend gut vorbereitet und über adäquate Qualifikationen verfügt, mit seinen Schülern in den Dialog zu treten ${ }^{8}$.

Der Religionslehrer und Katechet soll in hohem Maß sein Wissen über die Welt sowie die grundlegenden gesellschaftlich-sittlichen und ästhetischen Normen in sein Leben einbinden. So kann er zu dem werden, der in seinem eigenen Leben die Ideale von der Wahrheit, dem Guten und dem Schönen verkörpert ${ }^{9}$. Gerade in seiner Fähigkeit, die natürlichen, sozialen und kulturellen

6 Vgl. H. Hamer, Klucz do efektywności nauczania, Warszawa 1994, S. 15; Sukces wychowawczy $w$ relacjach stuchaczy podyplomowego studium wychowania prorodzinnego w Rzeszowie, Hrsg. J. Homplewicz, Rzeszów 1999.

7 „Wie sollten wir nicht wünschen, dass für alle sich die Initiativen vermehren, die sich für ihre christliche Bildung durch geeignete Hilfsmittel einsetzen (audiovisive Anlagen, Kleinschriften, Begegnungen und Vorträge), so dass viele Erwachsene eine ungenügend oder mangelhaft gebliebene Katechese ergänzen, auf höherem Niveau als dem in der Kindheit erreichten harmonisch vervollkommnen oder sich auch in diesem Bereich derart weiterbilden können, dass sie noch ernsthafter anderen zu helfen vermögen". Catechesi tradendae 45.

8 Vgl.M. Madej-Babula,Edukacjazintegrowana w dialoguz wychowaniem religijnym, Kraków 2006; Dzisiejszy katecheta. Stan aktualny i wyzwania, Hrsg. J. Stala, Kraków 2002; Dzisiejszy katechizowany. Stan aktualny $i$ wyzwania, Hrsg. J. Stala, Kraków 2002; Katechizować dzisiaj. Problemy $i$ wyzwania, Hrsg. J. Stala, Kielce 2004; B. Bilicka, Kościót w polskich katechizmach i podręcznikach do nauki religii dla dzieci i młodzieży w latach 1945-2001, Torun 2009; B. Bilicka, Jaki podręcznik do nauki religii dla młodzieży w XXI wieku?, „Teologia i Człowiek” 17 (2011), S. 161-176; Wychowanie do wartości w świecie cyberkultury, Hrsg. B. Bilicka, Torun 2012.

9 „Von der mündlichen Unterweisung der Apostel über die Briefe, die man unter den jungen Kirchen in Umlauf brachte, bis zu den modernsten Hilfsmitteln hat die Katechese nicht aufgehört, nach den geeignetsten Wegen und Mitteln für ihre Aufgabe zu suchen unter aktiver Beteiligung von Gemeinschaften und der Anleitung der Hirten. Dieses Bemühen muss fortgesetzt werden. Ich denke spontan an die großen Möglichkeiten, welche die sozialen Kommunikationsmittel und die Medien der Gruppenkommunikation bieten: Fernsehen, Radio, Presse, Schallplatten und bespielte Tonbänder, der gesamte audiovisuelle Bereich. Die auf diesem Gebiet unternommenen Anstrengungen sind derart, dass sie zu den größten Hoffnungen berechtigen. Die Erfahrung zeigt zum Beispiel die tiefe Wirkung einer Radio- oder Fernsehkatechese, wenn sie geschmackvollen Stil von Niveau mit vorbehaltloser Treue zum Lehramt zu verbinden weiß. Die Kirche hat heute viele Gelegenheiten, diese Probleme zu behandeln - darin eingeschlossen auch Tage der sozialen Kommunikationsmittel -, ohne dass es trotz ihrer grundlegenden Bedeutung erforderlich wäre, hier näher darauf einzugehen". Catechesi tradendae 46. 
Erscheinungen richtig zu erkennen und das Gute und Schöne wertzuschätzen, liegt ein Geheimnis pädagogischer Erfolge. Anscheinend hat für die Arbeit des Religionslehrers und Katecheten der Reichtum der Persönlichkeit besondere Bedeutung, denn wenn er anderen etwas geben will - muss er selbst viel besitzen, wenn er andere lehren will - muss er selbst gründlich gebildet sein, wenn er will, dass andere sich bessern - muss er selbst gut sein. Man kann nur dann von einer dynamischen Entwicklung der persönlichen Werte des jeweiligen Religionslehrers und Katecheten sprechen, wenn er aus sich selbst heraus oder aufgrund des Einwirkens anderer beständig danach strebt klüger, besser und empfindsamer für die Wahrheit, das Gute und das Schöne zu werden, aber auch die ihm Anvertrauten dahingehend motiviert, sich selbst in diese Richtung zu entwickeln ${ }^{10}$. Der Religionslehrer und Katechet sollte ein Mensch mit klar definierten Grundsätzen und einem weiten Horizont sein. Er verfügt über Autorität, weil er auf der einen Seite die Sendung Jesu Christi, des Meisters, erfüllt und sich auf der anderen Seite seinen Schülern freundschaftlich zuwendet. Er ist ein Gelehrter in seinem Fachbereich und kennt die Seelen der Kinder und Jugendlichen genau. Sein Denken ist systematisch, seine Unterrichtsplanung kontinuierlich und dadurch aufrichtig und spontan. Der große Reichtum und die Vielseitigkeit seiner Persönlichkeit im privaten wie im öffentlichen Leben geben ein authentisches Beispiel ${ }^{11}$.

Hier soll auch auf das in der pädagogisch-katechetischen Literatur erwähnte „pädagogische Talent” Bezug genommen werden, das ebenso permanent zu vervollkommnen ist. Es besteht aus dem Einfühlungsvermögen, mit dem sich der Religionslehrer und Katechet in die psychische Situation anderer Menschen versetzen kann, und aus einer besonderen Beobachtungsgabe, mit der er Material für eigene Erfahrungen sammeln kann. Wichtig ist ebenso der

${ }^{10}$ Vgl. W. Okoń, Wszystko o wychowaniu, Warszawa 1999, S. 246-247; J. Bagrowicz, Towarzyszyć wzrastaniu. Z dyskusji o metodach i środkach edukacji religijnej młodzieży, Toruń 2006; J. Bagrowicz, Edukacja religijna wspótczesnej młodzieży. Źródła i cele, Toruń 2000; A. Skreczko, Wychowanie domowe, Białystok 2011; A. Skreczko, Jan Pawet wychowawca mlodzieży, „Episteme” 105 (2012), S. 157-175.

${ }^{11}$ Vgl. J. Stala, Lasst uns voller Hoffnung vorwärts gehen. Pädagogisch-katechetische Aspekte, wie der Christ die Zeichen der Zeit in der gegenwärtigen Welt aufnimmt, „Roczniki liturgiczne“ 1 (56) (2009), S. 435-447; J. Stala, Familie und Schule: Zwei Erziehungsumfelder und Ihre Rolle im Rahmen der Erziehung, „Roczniki Teologiczne” 55 (2008), Vol. 8, S. 101-112; J. Stala, Die Erzieherischen Umfelder und Ihre Rolle im Rahmen der Erziehungsaufgaben, „Studia Teologiczno-Historyczno Śląska Opolskiego" 27 (2007), S. 375-383. 
sog. elterliche Instinkt ${ }^{12}$, mit dem er die Entwicklung des Schülers akzeptieren, dessen Gefühle ablesen (Empathie) und sich auf die aktuelle Wirklichkeit einstellen kann, was eine kritische Bewertung seines Handelns ermöglicht. Das Hauptmerkmal des ,pädagogischen Talents” ist jedoch die Fähigkeit, soziale Kontakte zu knüpfen ${ }^{13}$. In seiner Funktion als Lehrer ist es notwendig, dass der Religionslehrer und Katechet über ein gutes Gedächtnis verfügt, mit dem er sich die Vor- und Nachnamen der Schüler leicht aneignen und so direkt und herzlich mit ihnen in Kontakt treten kann. Ein gutes Gedächtnis erleichtert es, die Beteiligung der Schüler am Religionsunterricht und an der Katechese ebenso adäquat zu bewerten wie ihr Verhalten in der Schule. Darüber hinaus ist es ebenso hilfreich, um sich Orientierung zu verschaffen, aus welchen Milieus die Schüler kommen und unter welchen Bedingungen sie leben. Denn das Wissen über die Schüler ist eine der wichtigsten Bedingungen für eine fruchtbare Erziehungs- und Bildungsarbeit ${ }^{14}$.

Der Religionsunterricht und die Katechese sind Verkündigung des Wortes Gottes, ein religiöser Akt, gleichzeitig aber auch eine methodische Angelegenheit. Nur durch methodische Korrektheit kann ihr Erfolg erzielt werden ${ }^{15}$. Das Wort Gottes wirkt nicht auf magische Weise sondern

${ }_{12}$ Vgl. E. Osewska, J. Stala, W kierunku katechezy rodzinnej, Kielce 2003; J. Stala, Familienkatechese in Polen um die Jahrhundertwende. Probleme und Herausforderungen, Tarnów 2008; J. Stala, Katecheza rodzinna w nauczaniu Kościoła od Soboru Watykańskiego II, Tarnów 2009; J. Stala, Die Familie als Erziehungsgemeinschaft in der Perspektive des Familienkatechumenats, „Vox Patrum“ 27 (2007), Vol. 50-51, S. 487-496.

${ }_{13}$ Vgl. M. Majewski, Przegląd problematyki pedeutologicznej, in: Postawy katechetów, Hrsg. M. Majewski, Kraków 1996, S. 17-18; Katechizacja różnymi metodami, Hrsg. M. Majewski, Kraków 1994; E. Prijatelj, Psiholoska dinamika rasti v veri, Maribor 2008; B. Kluska, Uczeń Ikona Chrystusa. Studium egzegetyczno-teologiczne Mowy pożegnalnej J 13,31-16,33, Lublin 2007; N. Bravena, Philosophizing with Children on National Tradition Related to Christmas, in: Symetrical communication? Philosophy and Theology in Classrooms across Europe, Hrsg. F. Kraft, H. Roose, G. Büttner, Loccum 2011, S. 61-74.

${ }^{14}$ Vgl. Wychowanie dzieci w wieku przedszkolnym, Hrsg. E. Osewska, J. Stala, Tarnów 2005; Wychowanie dzieci w młodszym wieku szkolnym, część II: Wychowanie religijne i katecheza, Hrsg. Hrsg. J. Stala, Tarnów 2006; Wychowanie młodzieży w średnim wieku szkolnym, Część I: Wychowanie ogólne, Hrsg. J. Stala, Tarnów 2007; Wychowanie młodzieży w średnim wieku szkolnym, Część II: Wychowanie religijne i katecheza, Hrsg. J. Stala, Tarnów 2007; Wychowanie młodzieży na poziomie szkót ponadgimnazjalnych, Część I: Wychowanie ogólne, Hrsg. J. Stala, Tarnów 2007; Wychowanie młodzieży na poziomie szkót ponadgimnazjalnych, Część II: Wychowanie religijne i katecheza, Hrsg. J. Stala, Tarnów 2007; Katecheza dorostych, Hrsg. K. Misiaszek, J. Stala, Tarnów 2009.

15 „Das Alter und die geistige Entwicklung der Christen, der Grad ihrer kirchlichen und religiösen Reife und viele andere persönliche Umstände machen es erforderlich, dass die Katechese sehr verschiedene Methoden verwenden muss, um ihr eigentliches Ziel, die Glaubenserziehung, 
fällt dann auf fruchtbaren Boden, wenn es in Übereinstimmung mit den Bedingtheiten der menschlichen Natur weiter gegeben wird. Denn ein unzutreffend begründetes Ziel, eine unspezifische Struktur der Unterrichtseinheit, eine falsch formulierte Frage, ein unpassendes oder schlecht ausgewähltes Bild oder Foto können dazu führen, dass das Wort Gottes nicht richtig aufgenommen oder sogar überhaupt nicht empfangen wird und dass es seine Aufgabe nicht erfüllt ${ }^{16}$. In der heutigen Zeit lässt sich außerdem bemerken, dass der Religionslehrer und Katechet in seiner Funktion als Lehrer noch vor weitaus größeren Herausforderungen steht. Sowohl die Lehrer der anderen Fächer als auch die Schüler würden im Religionslehrer und Katecheten gern eine vortreffliche christliche Persönlichkeit und damit ein moralisches Ideal sehen ${ }^{17}$.

\section{Der Religionslehrer und Katechet als Erzieher}

Für einen guten Religionslehrer und Katecheten sind die erzieherischen Elemente seiner Arbeit von gleichrangiger Bedeutung. Diesem Faktor schenken die grundlegenden Dokumente der Kirche zur Katechese ${ }^{18}$ besondere Beachtung: „die Katechese ist eine Glaubenserziehung von Kindern, Jugendlichen und Erwachsenen, die vor allem eine Darbietung der christlichen Lehre umfasst, wobei man im allgemeinen organisch und systematisch vorgeht, um die Schüler in die Fülle des christlichen Lebens

zu erreichen. Diese Verschiedenheit ist ferner auf einer allgemeineren Ebene auch durch das soziokulturelle Milieu gefordert, in dem die Kirche ihre katechetische Tätigkeit ausübt”. Catechesi tradendae 51.

${ }^{16}$ Vgl. J. Mastalski, Samotność globalnego nastolatka, Kraków 2007; J. Mastalski, Szkolne interakcje zaburzajace skuteczne wychowanie, Kraków 2005.

${ }_{17}$ Vgl. E. Majcher, Osobowość katechety, in: Katecheza w szkole, Hrsg. J. Krucina, Wrocław 1992, S. 137.

18 „Allgemein kann man hier davon ausgehen, dass die Katechese eine Glaubenserziehung von Kindern, Jugendlichen und Erwachsenen ist, die vor allem eine Darbietung der christlichen Lehre umfasst, wobei man im allgemeinen organisch und systematisch vorgeht, um die Schüler in die Fülle des christlichen Lebens einzuführen. So verstanden ist die Katechese, ohne formal damit zusammenzufallen, mit einer gewissen Zahl von Seelsorgsaufgaben der Kirche verknüpft, die einen katechetischen Aspekt haben oder die Katechese entweder vorbereiten oder aus ihr folgen: die erste Verkündigung des Evangeliums oder die missionarische Predigt des Kerygmas, um den Glauben zu wecken, die Apologetik oder das Bemühen um Vernunftgründe für den Glauben, die Erfahrung des christlichen Lebens, die Feier der Sakramente, die Integration in die kirchliche Gemeinschaft sowie das apostolische und missionarische Zeugnis". Catechesi tradendae 18. 
einzuführen”"19, oder auch: „Die Ausbildung wird versuchen, im Katecheten die erzieherische Fähigkeit zur Reife zu bringen [...].Wie bei jeder Kunst ist auch hier das Wichtigste, dass der Katechet seinen eigenen Stil, Katechese zu erteilen, erwirbt, indem er die allgemeinen Grundsätze der katechetischen Pädagogik seiner Persönlichkeit anpasst" ${ }^{20}$.

Bei der Reflexion über diese Dimension der Bildung bewahrheitet sich erneut, dass Jesus Christus der einzige Lehrer und der einzige Erzieher für alle Menschen ist, dem der Religionslehrer und Katechet lediglich dient. Denn allein Jesus Christus lehrt und erzieht. Von daher ist der Religionslehrer und Katechet Lehrer und Erzieher in dem Ausmaß, wie er Verkünder und Übersetzer der Frohen Botschaft bleibt, aber keinesfalls seine eigenen Weltanschauungen und Einschätzungen verbreitet. Wenn der Religionslehrer und Katechet erfolgreich wirken will, dann muss er innerlich und äußerlich, also authentisch im Leben und Handeln sowie mit dem im Einklang sein, was er selbst verkündet. Es geht darum, dass der Religionslehrer und Katechet zu einer psychischen Wirklichkeit wird, die für seine Schüler gut lesbar und offen ist, damit Vertrauen wachsen kann. Eine bedeutende Rolle im Religionsunterricht und in der Katechese spielt der zwischenmenschliche Kontakt, durch den der Religionslehrer und Katechet förderlich auf seine Schüler einwirken kann und deren Persönlichkeit, ihre Sehnsüchte und Träume, ihre Vorlieben, die materielle und atmosphärische Situation in ihrem Zuhause kennen lernt. Ein wesentliches Merkmal seiner Persönlichkeit, das einen derartigen Kontakt erleichtert, sind eine positive Einstellung zu den Schülern und deren Problemen, die Fähigkeit sich in ihre Lage hinein zu versetzen und sich mit ihnen zu identifizieren. Ganz offensichtlich hängen alle diese Merkmale von psychischen Kenntnissen, vom psycho-physischen Entwicklungsgrad und von den Bedürfnissen der dem Religionslehrer und Katecheten anvertrauten Kinder und Jugendlichen $\mathrm{ab}^{21}$.

Viele Pädagogen erachten auch die Intuition, die Suggestivität und den pädagogischen Takt für besonders bedeutend bei der Erziehung. Intuitive Erkenntnis konzentriert sich auf die umfassende Erkenntnis des Objekts

19 Katechismus der Katholischen Kirche 5.

${ }^{20}$ Directorium catechisticum generale 244.

${ }^{21} \mathrm{Vgl}$. E. Prijatelj, Izziv teorij o psihološki dinamiki ženskega verovanja, "Bogoslovni vestnik" 68 (2008) 1, S. 113-122; J. Vodičar, Muss man die Globalisierung unterrichten?, „Synthesis philosophica” (2009) 2, S. 281-295; S. Gerjolj, Ideologie und Bildung, Gießen 1997. 
der Erziehung. Im Erziehungsprozess ist sie insbesondere bei überraschend auftretenden Situationen unverzichtbar. Die Suggestivität besteht darin, dass sich im Zögling nachdrücklich eine gewisse Grundhaltung ausbildet, dass dieser den ausgeübten Nachdruck nicht als solchen empfindet sondern vielmehr davon überzeugt ist, alles freiwillig anzunehmen, mit dem er beschenkt wird. Die Kraft seines suggestiven Einwirkens leitet sich aus der Persönlichkeit des Erziehers ab. Der pädagogische Takt führt dazu, dass die Erziehung in Einklang mit festgelegten Prinzipien, auf der Basis spezifischer Grundsätze und Methoden sowie unter der Berücksichtigung der Lebensbedingungen, vor allem jedoch der Bedürfnisse und der psychischen Lage des Zöglings erfolgt. Ein taktvoller Erzieher ist geradlinig, auf dem Weg hin zu seinen Zielen auch konsequent, dabei jedoch flexibel beim Einsatz seiner Mittel zur Einflussnahme. Er kann sich ebenso kritisch gegenüber verschiedenen Konzeptionen verhalten und daraus die Werte auswählen, die dem Wohl des Zöglings am besten dienen. Darüber hinaus gibt er sich natürlich, gewinnt das Vertrauen der ihm anvertrauten Schüler und sucht die Zusammenarbeit mit ihnen. Gleichzeitig vermag er zu loben, wenn das Lob auch wirklich verdient ist. Er schätzt die Achtung richtig ein, die ihm entgegen gebracht wird, und zeigt sich dankbar, wird jedoch nie Ehrerbietung gegenüber seiner eigenen Person verlangen. Der Religionslehrer und Katechet ist ein Erzieher, der seine Berufung liebt, noch mehr aber seine Schüler, an die er den Glauben weitergibt. Er bereitet seine Stunden solide vor und führt sie auf interessante Weise durch, kann dabei auch humorvoll sein, herzliche Freundschaftlichkeit und natürliche Wertschätzung zeigen ${ }^{22}$.

Die Glaubensschüler erwarten von ihrem Religionslehrer und Katecheten eine humorvolle und freudvolle Grundeinstellung. Die Ergebnisse von durchgeführten Untersuchungen zeigen, dass mehr als drei Viertel aller befragten Jugendlichen sich einen Religionslehrer und Katecheten wünschen, der fröhlich, lächelnd, nett und humorvoll ist und der auch gerne mit ihnen singt. Das Lächeln des Religionslehrers und Katecheten bringt eine Atmosphäre gegenseitigen Vertrauens zwischen den Erziehern und den zu erziehenden Kindern und Jugendlichen in die Schule, was bei den letztgenannten das Gefühl von Sicherheit verstärkt. Es geht hierbei um ein authentisches, einfaches und

${ }^{22}$ Vgl. M. Majewski, Przeglad problematyki pedeutologicznej, in: Postawy katechetów, Hrsg. M. Majewski, Kraków 1996, S. 20-22; W trosce o integralne wychowanie, Hrsg. M. Nowak, T. Ożóg, A. Rynio, Lublin 2003; Elementy chrześcijańskie w edukacji ekologicznej, Hrsg. M. Ostrowski, J. Partyka, Ojców 2008. 
herzliches Lächeln als Ausdruck der Sympathie für die Schüler, das eine der erfolgreichsten Erziehungsmethoden darstellt ${ }^{23}$.

Der Heilige Vater Johannes Paul II. erinnerte gern daran, dass eine Grundbedingung für erfolgreiches erzieherisches Wirken die Liebe ist, die dem jungen Menschen höhere Ideale aufzeigen und ihn auf dem Weg dahin begleiten will, diese auch zu erreichen. Nur dank der liebevollen Einstellung kann der Religionslehrer und Katechet weit gefächerte Perspektiven vor den Glaubensschülern ausbreiten, kann er ihnen Hilfe bei der Bewältigung von Problemen und bei der kontinuierlichen Selbstvervollkommnung anbieten ${ }^{24}$. Eine derartige Liebe gründet im Interesse für die Welt des Schülers, in der Anteilnahme an seinen Sorgen und Freuden, in der Bereitstellung von Hilfsangeboten, in Güte, Fürsorge und Betreuung, im Vermitteln eines Sicherheitsgefühls, in der Zeit, die er sich für den Schüler nimmt, aber auch darin, dass er ihm Anforderungen stellt und deren Erfüllung überprüft. Die liebevolle Grundhaltung führt außerdem dazu, dass die vermittelten Wahrheiten stets mit neuer Frische angenommen werden und dass der Schüler mit seinen Sorgen, Problemen und Nöten gerne zu seinem Erzieher kommt ${ }^{25}$.

\section{Der Religionslehrer und Katechet als Glaubenszeuge}

Der Religionslehrer und Katechet, der als Erzieher fungiert, steht vor der außerordentlich wichtigen Aufgabe, eine im weiten Sinn verstandene christliche Bildung zu vermitteln, in der seine authentische Persönlichkeit und seine umfangreiche religiöse Erfahrung eine grundlegende Rolle spielen werden, womit sein Glaubenszeugnis durch ein wahrhaft christliches Leben in enger Verbindung steht ${ }^{26}$. Der Prozess der Glaubensentwicklung vollzieht

${ }^{23} \mathrm{Vgl}$. C. M. Sondej, Intelektualna $i$ duchowa formacja osobowości katechetek w Międzyzakonnym Wyższym Instytucie Katechetycznym w Krakowie, Kraków 1998, S. 254; Nauczyciel i rodzina w świetle specjalnych potrzeb edukacyjnych dziecka (Szkic monograficzny), Hrsg. A. Stankowski, Katowice 2008.

${ }^{24}$ Vgl. E. Tkocz, Chrześcijańska formacja młodzieży $w$ świetle orędzi Jana Pawła II na Światowe Dni Młodzieży, Katowice 2005; Wychowanie chrześcijańskie. Między tradycja a wspótczesnościa, Hrsg. A. Rynio, Lublin 2007; E. Domagała-Zyśk, Autonomia czy odtaczenie? Rola osoby znaczacej w życiu młodzieży z trudnościami w nauce, Lublin 2004.

${ }^{25}$ Vgl. J. Szpet, Dydaktyka katechezy, Poznań 1999, S. 266.

${ }^{26}$ Vgl. H. Słotwińska, Ksztaltowanie postaw religijnych na katechezie, Lublin 2004; H. Słotwińska, Wychowawcza rola wzorów osobowych, Lublin 2008. 
sich in der Katechese durch Lehre und Erziehung, aber vor allem durch das Glaubenszeugnis. Der Religionslehrer und Katechet muss also Lehrer, Erzieher und gleichzeitig auch Glaubenszeuge sein. Aufgabe der Kirche ist es, das Sakrament der Begegnung des Menschen mit Gott zu wahren und dies durch die Vergegenwärtigung und Sichtbarmachung von Gott Vater und Seinem Sohn anzustreben, der durch die beständige Erneuerung leibhaftig wird. Dabei überlässt sie sich der reinigenden Führung des Heiligen Geistes. Dies geschieht in der Hauptsache durch ein lebendiges Zeugnis und einen gereiften Glauben ${ }^{27}$. Denn der Katechet tritt im Namen der Kirche als Zeuge der christlichen Botschaft auf, der seinen Nächsten dient, mit ihnen die Früchte des eigenen gereiften Glaubens teilt und aufkluge Weise die gemeinsame Suche dahin leitet, damit das angestrebte Ziel erreicht wird. Das Glaubenszeugnis des Religionslehrers und Katecheten sowie das gesamte prophetische Wirken der Kirche sind die Beteiligung am einzigen Zeugnis Jesu Christi. Im Evangelium vertraute Jesus den Aposteln die standhafte Verkündung des Wortes an, nachdem er sie über einige Jahre hinweg ausgewählt, sie in einer freundschaftlichen Atmosphäre ausgebildet, sie schließlich eingesetzt und als Zeugen und Lehrer der Heilsbotschaft ausgesandt hatte ${ }^{28}$.

Die eigentliche Aufgabe des Religionslehrers und Katecheten besteht darin, aufzuzeigen wer Jesus Christus ist: Er soll Sein Leben und Sein Geheimnis und den christlichen Glauben als Nachfolge Seiner Person darstellen ${ }^{29}$. Damit der Religionslehrer und Katechet diese Bestimmung erfüllen kann, muss er selbst tief in einem Glauben verwurzelt sein, der nicht nur das Fundament seines katechetischen Dienstes sondern seines gesamten Lebens ausmachen

27 „So wie das menschliche Schaffen aus dem Menschen hervorgeht, so ist es auch auf den Menschen hingeordnet. Durch sein Werk formt der Mensch nämlich nicht nur die Dinge und die Gesellschaft um, sondern vervollkommnet er auch sich selbst. Er lernt vieles, entwickelt seine Fähigkeiten, überschreitet sich und wächst über sich empor. Ein Wachstum dieser Art ist, richtig verstanden, mehr wert als zusammengeraffter äußerer Reichtum. Der Wert des Menschen liegt mehr in ihm selbst als in seinem Besitz. Ebenso ist alles, was die Menschen zur Erreichung einer größeren Gerechtigkeit, einer umfassenderen Brüderlichkeit und einer humaneren Ordnung der gesellschaftlichen Verflechtungen tun, wertvoller als der technische Fortschritt. Dieser technische Fortschritt kann nämlich gewissermaßen die Basis für den menschlichen Aufstieg bieten; den Aufstieg selbst wird er von sich allein aus keineswegs verwirklichen. Richtschnur für das menschliche Schaffen ist daher, dass es gemäß dem Plan und Willen Gottes mit dem echten Wohl der Menschheit übereinstimme und dem Menschen als Einzelwesen und als Glied der Gesellschaft gestatte, seiner ganzen Berufung nachzukommen und sie zu erfüllen". Gaudium et spes 35 .

${ }^{28}$ Directorium catechisticum generale 137.

${ }_{29}$ Vgl. Directorium catechisticum generale 41. 
soll. Durch persönliche Erlebnisse erwirbt er sich die reale Chance Zeugnis des Glaubens abzulegen. Es gibt kein Glaubenszeugnis ohne die eigene Erfahrung der Macht Jesu Christi. Der Glaube des Religionslehrers und Katecheten wird zum Bezugspunkt und zur Basis für den Glauben derer, an die sich die Katechese richtet. Glaubensschüler und Glaubenslehrer können gemeinsam in ihrem Glauben wachsen. Einzig das Zeugnis vermag wirkliche Faszination auszulösen und in diejenigen Werte einzuführen, die das Wort allein nicht vermitteln kann. Der Religionslehrer und Katechet muss Gott und die Wahrheit authentisch bezeugen, die er verkündet. Sein ausgesprochenes Wort verliert sofort an Wert, wenn es nicht mit dem Leben übereinstimmt und nicht aus dem Herzen kommt. Wenn es jedoch seiner tiefen Überzeugung entspringt, wird es die Adressaten der Katechese für Jesus Christus gewinnen und sie mit Ihm vereinigen. Der gereifte, lebendige und wahrhafte Glaube des Religionslehrers und Katecheten macht die „Seele” jeder Religionsstunde und Katechese aus. Er führt zum persönlichen Dialog mit Gott hin. Die Grundlage dieses Dialogs ist das Wort Gottes, das der Religionslehrer und Katechet hören, verstehen sowie als wichtigsten Wert anerkennen kann und nach dem er sein eigenes Leben ausrichten wird. Folglich ist er durch seinen eigenen Lebensstil imstande, seinen Glaubensschülern die Werte weiterzugeben, die er sich selbst zueigen gemacht hat. Er wird sie zur Freundschaft mit Gott geleiten, diese Freundschaft mit Leben erfüllen und beständig vertiefen. Es ist eben die Harmonie zwischen dem Gebet, dem sakramentalen Leben und dem Alltagsleben, welche die Glaubensschüler bei ihrem Religionslehrer und Katecheten wahrnehmen können und die zu einem machtvollen Mittel wird, damit diese selbst eine derartige Grundeinstellung ausbilden und den Wunsch nach innerer Veränderung entwickeln wollen ${ }^{30}$.

Das Glaubenzeugnis, das der Religionslehrer und Katechet durch sein Leben und seine Grundhaltung ablegt, ist Zeichen, Begegnung, Einladung aber auch Verpflichtung. Die Kirche bezeugt das Leben nach dem Tod und eine eschatologische Zukunft, vor allem ist sie jedoch das soziale Zeichen der Liebe. Darum muss das Glaubenszeugnis, wenn es zu einem Zeichen werden soll, in emotionaler, darüber hinaus aber ebenso in österlicher und gemeinschaftlicher Hinsicht dynamisch ist. Das Zeugnis muss sowohl als

${ }^{30}$ Vgl. P. Duksa, Strategie skuteczności szkolnego nauczania religii w Polsce. Studium pedagogicznoreligijne w wymiarze interdyscyplinarnym, Olsztyn 2007; Cz. Sandecki, Katecheza szkolna a religijność polskich studentów, Kraków 2004. 
individuelle wie als gemeinsame Begegnung eine Begegnung mit Christus und in Christus sein. Inhalt dieser Begegnung sollen die Person selbst wie auch Ereignisse und Worte sein, die mit Jesus Christus in Verbindung stehen, Ziel dieser Begegnungen stellen Gedanken und Erläuterungen zu Seiner Botschaft ebenso dar wie die Entdeckung des Liebesgebotes und die Verwirklichung des Evangelisierungsprogramms. Das Wesen der Einladung ist die gegenseitige Offenheit von Person zu Person und eine wohlwollende Einstellung den anderen gegenüber. So wird eine günstige Atmosphäre geschaffen, in der man die gemeinsamen Werte, Erlebnisse und Vorschläge bereitwillig miteinander teilt. Als Einladung hat das Glaubenszeugnis also einen übernatürlichen Charakter. Als ideale Einladung erlaubt es das Zeugnis, in das Geheimnis des göttlichen Lebens in uns vorzudringen und es in der Gemeinschaft zu teilen. Als Verpflichtung ist das Glaubenszeugnis die Konsequenz aus der Zugehörigkeit zu Jesus Christus und Seiner Kirche ${ }^{31}$. Der Religionslehrer und Katechet muss sich bewusst sein, dass didaktische Fähigkeiten, tiefgründiges religiöses Wissen oder sogar die wohlwollende Akzeptanz der Glaubensschüler allein nicht ausreichen. Gerade heute gibt es einen großen Bedarf an Religionslehrern und Katecheten, welche die aktuellen Schwierigkeiten zusammen mit den Jugendlichen angehen, gemeinsam Lösungen für deren Probleme aufspüren und Tag für Tag Zeugnis für Jesus Christus ablegen, der die Verlorenen sucht, denn „der heutige Mensch hört lieber auf Zeugen als auf Gelehrte, und wenn er auf Gelehrte hört, dann deshalb, weil sie Zeugen sind"32.

Zusammen mit den Dimensionen, die sich auf das Sein und das Wissen beziehen, soll die Ausbildung des Religionslehrers und Katecheten im gleichen Umfang seine Handlungskompetenzen entwickeln und fördern. Weil die Katechese ein Kommunikationsakt ist, muss jeder, der den Dienst als Religionslehrer oder Katechet aufnehmen will, eine entsprechende

${ }^{31}$ Vgl. A. Potocki, Wychowanie religijne $w$ polskich przemianach. Studium socjologiczno - pastoralne, Warszawa 2007; S. H. Zaręba, Dynamika świadomości religijno-moralnej młodzieży w warunkach przemian ustrojowych w Polsce (1988-1998), Warszawa 2003; A. Rynio, Integralne wychowanie w myśli Jana Pawła II, Lublin 2004; A. Rynio, Wychowanie młodzieży w nauczaniu kardynała Stefana Wyszyńskiego, Lublin 2001; W. Rzepa, Odpowiedzialność moralna w kontekście ludzkiej wolności, Lublin 2009.

${ }^{32}$ Evangelii nuntiandi 41. 
Vorbereitung in pädagogischer und katechetischer Hinsicht erhalten. Katechetisches Wirken ist Teilnahme an der Pädagogik Gottes, deshalb soll diese Ausbildung versuchen, im Katecheten die erzieherische Fähigkeit zur Reife zu bringen; sie beinhaltet: die Fähigkeit, auf die Menschen einzugehen, die Geschicklichkeit, die Nachfrage nach Erziehung zu deuten und ihr $\mathrm{zu}$ entsprechen, die Initiative, Lernprozesse in Gang $\mathrm{zu}$ bringen, und die Kunst, eine Menschengruppe zur Reife zu führen ${ }^{33}$. Der Religionslehrer und Katechet muss dazu befähigt werden, unter Abwägung der Umstände das erzieherische Wirken in der Katechetengruppe zu organisieren, einen realistischen Plan auszuarbeiten und diesen - nach seiner Verwirklichung - kritisch zu beurteilen. Er soll imstande sein, eine Gruppe zu leiten, indem er in kluger Weise Techniken der Gruppendynamik anwendet, wie sie die Psychologie anbietet ${ }^{34}$. Um diese Ziele zu erreichen, muss sich der Religionslehrer und Katechet besonders dessen bewusst sein, dass er dazu aufgefordert und verpflichtet ist, die Mission eines wahrhaften Lehrers, eines authentischen Erziehers und eines glaubwürdigen Zeugen zu erfüllen. Daher ist es von großer Bedeutung, in dieser Hinsicht die Aufgaben und die Bildungsrichtlinien zu präzisieren. Die Ausbildung pädagogischer und katechetischer Fertigkeiten zeigt, welch außerordentlich schwieriger Problemkreis darin besteht, von der Theorie und der Doktrin zur Praxis der Katechese überzugehen. Auf dem Religionslehrer und Katecheten, der die Wahrheit über die Erlösung kennt, ruht eine Aufgabe von wesentlicher Bedeutung, denn er wird für seine Schüler zum Lehrer, Erzieher und Glaubenszeugen ${ }^{35}$. Dies erfordert von ihm, dass er neuartige Situationen und Aufgaben selbstständig und kreativ bewältigen und auf die unterschiedlichen Geschehnisse lebendig reagieren kann. Dazu muss er je nach Bedarf über einen scharfsinnigen Verstand, analytische Fähigkeiten oder auch eine synthetische Herangehensweise an Ereignisse verfügen. Deshalb soll den Religionslehrer und Katecheten die Bereitschaft auszeichnen, sein Wissen kontinuierlich zu erweitern und sich für die eigene Weiterbildung und ein breites Interessenspektrum zu begeistern.

\footnotetext{
${ }^{33}$ Vgl. B. Stańkowski, Wychowanie w duchu wielokulturowości, Kraków 2007.

${ }^{34} \mathrm{Vgl}$. Directorium catechisticum generale 244-245.

${ }_{35}$ Vgl. Z. Włodarski, Człowiek jako wychowawca i nauczyciel, Warszawa 1992.
} 


\section{Bibliography}

Bagrowicz J., Edukacja religijna współczesnej młodzieży. Źródła i cele, Torun 2000.

Bagrowicz J., Towarzyszyć wzrastaniu. Z dyskusji o metodach i środkach edukacji religijnej młodzieży, Toruń 2006.

Bilicka B., Kościół w polskich katechizmach i podręcznikach do nauki religii dla dzieci i młodzieży w latach 1945-2001, Toruń 2009.

Bravena N., Philosophizing with Children on National Tradition Related to Christmas, in: Symetrical communication? Philosophy and Theology in Classrooms across Europe, Hrsg. F. Kraft, H. Roose, G. Büttner, Loccum 2011, S. 61-74.

Domagała-Zyśk E., Autonomia czy odłaczenie? Rola osoby znaczącej w życiu młodzieży $z$ trudnościami w nauce, Lublin 2004.

Duksa P., Strategie skuteczności szkolnego nauczania religii w Polsce. Studium pedagogicznoreligijne w wymiarze interdyscyplinarnym, Olsztyn 2007.

Dydaktyka katechezy. Część I, Hrsg. J. Stala, Tarnów 2004.

Dydaktyka katechezy. Część II, Hrsg. J. Stala, Tarnów 2004.

Dzisiejszy katecheta. Stan aktualny i wyzwania, Hrsg. J. Stala, Kraków 2002.

Dzisiejszy katechizowany. Stan aktualny i wyzwania, Hrsg. J. Stala, Kraków 2002.

Gerjolj S., Ideologie und Bildung, Gießen 1997.

Harwas-Napierała B., Komunikacja interpersonalna w rodzinie, Poznań 2008.

Janke A.W., Transformacja w stosunkach rodziny i szkoły na przełomie XX/XXI wieku. Perspektyw zmiany społecznej w edukacji, Bydgoszcz 2002.

Katechizować dzisiaj. Problemy i wyzwania, Hrsg. J. Stala, Kielce 2004.

Kl'uska B., Uczeń Ikona Chrystusa. Studium egzegetyczno-teologiczne Mowy pożegnalnej J 13,31-16,33, Lublin 2007.

Lombaerts H., Osewska E., Family and Family Catechesis. A Matter of Diversification, „Acta Paedagogica Vilenensia” (2008), Vol. 20, S. 225-243.

Madej-Babula M., Edukacja zintegrowana w dialogu z wychowaniem religijnym, Kraków 2006.

Mastalski J., Samotność globalnego nastolatka, Kraków 2007.

Osewska E., Modele komunikacji interpersonalnej i ich znaczenie dla katechezy, in: Wybrane zagadnienia z katechetyki, Hrsg. J. Stala, Tarnów 2003, S. 111-139.

Osewska E., Możliwości i ograniczenia polityki rodzinnej w krajach Unii Europejskiej, in: Rodzina jako środowisko rozwoju człowieka, Hrsg. W. Piotrowski, Tarnów 2004, S. 89-119.

Osewska E., Stala J., Catholic School. Polish perspective, "Rivista lasalliana" 75 (2008) Nr. 2, S. 241-246.

Osewska E., Stala J., W kierunku katechezy rodzinnej, Kielce 2003.

Potocki A., Wychowanie religijne $w$ polskich przemianach. Studium socjologiczno - pastoralne, Warszawa 2007.

Prijatelj E., Psiholoska dinamika rasti v veri, Maribor 2008.

Rynio A., Integralne wychowanie w myśli Jana Pawła II, Lublin 2004.

Rzepa W., Odpowiedzialność moralna w kontekście ludzkiej wolności, Lublin 2009.

Sandecki Cz., Katecheza szkolna a religijność polskich studentów, Kraków 2004. 
Skreczko A., Wychowanie domowe, Białystok 2011.

Słowińska H., Kształtowanie postaw religijnych na katechezie, Lublin 2004.

Słowińska H., Wychowawcza rola wzorów osobowych, Lublin 2008.

Stala J., Die Erzieherischen Umfelder und Ihre Rolle im Rahmen der Erziehungsaufgaben, „Studia Teologiczno-Historyczno Śląska Opolskiego” 27 (2007), S. 375-383.

Stala J., Die Familie als Erziehungsgemeinschaft in der Perspektive des Familienkatechumenats, „Vox Patrum“ 27 (2007), Vol. 50-51, S. 487-496.

Stala J., Familie und Schule: Zwei Erziehungsumfelder und Ihre Rolle im Rahmen der Erziehung, „Roczniki Teologiczne” 55 (2008), Vol. 8, S. 101-112.

Stala J., Familienkatechese in Polen um die Jahrhundertwende. Probleme und Herausforderungen, Tarnów 2008.

Stala J., Lasst uns voller Hoffnung vorwärts gehen. Pädagogisch-katechetische Aspekte, wie der Christ die Zeichen der Zeit in der gegenwärtigen Welt aufnimmt, „Roczniki liturgiczne“" 1 (56) (2009), S. 435-447.

Stala J., Osewska E., Anders erziehen in Polen. Der Erziehungs- und Bildungsbegriff im Kontext eines sich ständig verändernden Europas des XXI. Jahrhunderts, Tarnów 2009.

Stala S., $W$ kierunku integralnej edukacji religijnej $w$ rodzinie. Próba refleksji nad nauczaniem Jana Pawła II w kontekście polskich uwarunkowań, Tarnów 2010.

Vodičar J., Muss man die Globalisierung unterrichten?, „Synthesis philosophica” (2009) 2, S. 281-295.

W trosce o integralne wychowanie, Hrsg. M. Nowak, T. Ożóg, A. Rynio, Lublin 2003.

Wychowanie chrześcijańskie. Między tradycja a współczesnościa, Hrsg. A. Rynio, Lublin 2007.

Wychowanie do wartości w świecie cyberkultury, Hrsg. B. Bilicka, Toruń 2012.

Zaręba S.H., Dynamika świadomości religijno-moralnej młodzieży w warunkach przemian ustrojowych w Polsce (1988-1998), Warszawa 2003. 